\title{
The impact of diabetes on labour market participation: a systematic review of results and methods
}

\author{
Sara Pedron ${ }^{1,2^{*}}$, Karl Emmert-Fees ${ }^{1}$, Michael Laxy ${ }^{1,2}$ and Lars Schwettmann ${ }^{1}$
}

\begin{abstract}
Background: Diabetes mellitus is a major chronic disease, which is connected to direct and indirect costs and productivity losses. However, its effects on labour market participation are not straightforward to identify, nor are they consistently included in cost-of-illness studies. First, this study aims to synthesise existing evidence regarding the impact of diabetes on labour market outcomes that imply a complete absence of work. Second, the analysis takes a particular look at relevant methodological choices and the resulting quality of the studies included.

Methods: We conducted a systematic literature research (PubMed, Embase, PsychINFO), by applying a standard screening, selection and results extraction process, which considered all types of studies including cross-sectional and longitudinal approaches. Risk-of-bias and quality within the studies were assessed and results were compared. We dedicated special attention to the modelling of potential reverse causality between diabetes and labour market outcomes and the consideration of comorbidities and complications.

Results: Overall, 30 studies satisfied our inclusion criteria. We identified four main labour participation outcomes: absence of employment, unemployment, early retirement, and disability pension. The studies reviewed show a negative impact of diabetes on the labour market participation outcomes considered. However, only a few studies controlled for endogeneity, differentiated between type 1 and type 2 diabetes or modelled the impact of comorbidities. We report how modelling choices affect the directions and interpretations of the effects.

Conclusions: The available evidence mainly suggests a negative impact of diabetes on several outcomes indicating labour market participation. The methodological limitations identified can guide future research with respect to both outcomes and methods. This study provides therefore an empirical contribution to the discussion on how to model the economic impact of diabetes.
\end{abstract}

Keywords: Diabetes mellitus, Labour market, Indirect cost, Employment, Unemployment, Early retirement, Disability pension, Systematic review

\section{Background}

Diabetes mellitus is a major chronic disease with increasing public health relevance in high-, low- and middle-income countries. According to recent estimates, the number of people suffering from this condition worldwide will rise from 425 million in 2017 to 629 million by 2045 [1]. The progressing prevalence of this illness is especially due to type 2 diabetes, which constitutes $90-95 \%$ of

\footnotetext{
* Correspondence: sara.pedron@helmholtz-muenchen.de

${ }^{1}$ Helmholtz Zentrum München $(\mathrm{GmbH})$, Institute of Health Economics and Health Care Management, Ingolstädter Landstraße 1, 85764 Neuherberg, Germany

${ }^{2}$ German Center for Diabetes Research (DZD), Neuherberg, Germany
}

diabetes cases, and the increasing average age of populations [2-5]. Due to this increase, total health care expenditures resulting from diabetes mellitus are estimated to rise from $\$ 727$ billion in 2017 to $\$ 776$ billion in 2045 [1].

Type 2 diabetes is closely linked to environmental and lifestyle risk factors, such as unhealthy diet, smoking and physical inactivity. Furthermore, the management of both type 1 and type 2 requires a high level of patient awareness and self-management [1]. For these reasons, many countries have established prevention and disease management programs to reduce incidence rates and to help affected people coping with the illness [6-8]. If

(c) The Author(s). 2019 Open Access This article is distributed under the terms of the Creative Commons Attribution 4.0 International License (http://creativecommons.org/licenses/by/4.0/), which permits unrestricted use, distribution, and reproduction in any medium, provided you give appropriate credit to the original author(s) and the source, provide a link to the Creative Commons license, and indicate if changes were made. The Creative Commons Public Domain Dedication waiver (http://creativecommons.org/publicdomain/zero/1.0/) applies to the data made available in this article, unless otherwise stated. 
poorly managed, both types of diabetes could lead to severe medical complications, which can affect an individual's ability to work and may lead to lower productivity at work (presenteeism) or missing workdays (absenteeism) [9].

Existing systematic reviews suggest a clear effect of diabetes on economic costs $[10,11]$, work ability, work functioning, macroeconomic productivity and socio-economic consequences [9-11]. Despite this evidence, most cost-of-illness studies base their calculations of indirect costs on productivity losses due to short or long term morbidity (absenteeism, presenteeism and disability pension) and mortality [12]. However, as suggested by the American Diabetes Association [13], considering only these factors might result in a rather conservative approach, since individuals with diabetes might have lower workforce participation rates than the overall population, which would not be adequately captured simply accounting for such short and long term productivity losses. Although the underestimation caused by this flaw could be mitigated by adopting a friction cost approach, the effect remains of key importance in the correct computation of individual and general societal costs due to diabetes.

However, understanding and empirically estimating the effects of diabetes on workforce participation is not straightforward. The correct empirical strategy to examine the relationship between diabetes and workforce participation requires careful consideration of potential confounding, of reverse causality between the illness and workforce participation - otherwise termed "endogeneity" -, of different types of diabetes mellitus and of its associated complications.

Given the growing importance of diabetes, the complex assessment of its productivity losses, and the potential heterogeneity in the applied econometric methods to address this question, a careful pooling and critical assessment of the existing evidence regarding the impact of diabetes on labour market participation is needed. Therefore, the aim of the present review is twofold: First, we gather all existing evidence regarding the relation between diabetes and workforce participation outcomes (employment/unemployment, early retirement, and permanent disability pension). Second, we distinguish and assess methodological characteristics in existing studies. Hence, this review contributes to the discussion on the appropriate modelling of diabetes impact, provides methodological guidance for future studies and, therefore, fosters informed decisions in health policy and research.

\section{Methods}

\section{Search strategy}

The review was conducted and reported following the PRISMA guidelines [14]. We applied a structured approach, combining keywords and Medical Subject Headings $\left(\mathrm{MeSH}^{\circ}\right)$ or Embase Subject Headings $\left(\right.$ Emtree $\left.^{\circ}\right)$ on diabetes and labour market outcomes. The full set of the search terms for one database is represented in detail in Additional file 1. We applied the search on three databases: PubMed, Embase and PsychINFO. All databases were accessed using our institutional login. Additionally, at the end of the selection process, eligible studies, but also economic modelling studies focusing on the impact of diabetes on the selected outcomes, were screened for references.

\section{Inclusion and exclusion criteria}

Included original studies had to be published in a peer-reviewed journal between 1st January 2000 and 28th March 2017 in any language and had to focus on the general population of adults aged 18-64. Papers focusing on women or specific ethnic groups were also considered eligible whereas studies, which only aim at specific subpopulations of patients suffering from other diseases were excluded. All articles screened by abstract had an English version of the abstract available, and for none of the eligible studies the use of a translator was necessary.

We focused on studies which evaluated the impact of diabetes or its biomarkers, such as hyperglycaemia or haemoglobin A1c (glycosylated haemoglobin) higher than $6.5 \%$ [15], on labour market outcomes indicating the complete absence of an occupation, i.e. employment, unemployment, early retirement or reception of a permanent disability pension, but not mortality or other measures of productivity covered in other reviews $[9,11]$. In addition, studies were considered not eligible if diabetes appeared as a cluster of several conditions (e.g. metabolic disorders, cardiovascular risk factors) or if the outcome of interest could not be distinguished from other outcomes.

We included both cross-sectional and longitudinal studies with the primary aim of estimating the impact of diabetes on the selected outcomes, while economic modelling studies (cost-of-illness studies and simulations) were not included.

\section{Study selection process}

After pooling the results in EndNote (Version X7) and eliminating duplicates, two authors (SP, KEF) carried out an independent three-step successive screening process of the articles regarding titles, abstracts and full-texts, by considering the predefined inclusion criteria described above. Disagreements were first discussed between the two authors and afterwards with the other authors (LS, ML).

\section{Data extraction and synthesis}

After the identification of all eligible studies, we collected the results by using a predefined extraction form based on the well-established Cochrane Consumers and Communication Review Group data template [16]. From each paper we extracted a standardised set of information including 
the general characteristics of the study, the data source and the study population, the outcome measure considered and its definition, the analysis method used, the type of results reported, and finally the magnitude of corresponding effects. For those studies, which take endogeneity into account, we also added the necessary information allowing the evaluation of their methodological rigor. In all cases, missing information was retrieved by consulting survey web pages, reading explanatory publications or contacting authors. Furthermore, we grouped the studies in four different outcome categories. Studies which analysed the impact of diabetes on a binary variable indicating the presence of an occupation were grouped under the term "employment". Other studies considered a binary variable indicating the absence of an occupation or the status "unemployment", i.e. currently not employed but actively looking for an occupation. Furthermore, we identified two other clusters, i.e. studies which focused on "early retirement" and studies which focused on the full receipt of a permanent "disability pension".

\section{Quality appraisal}

We assessed the quality and the risk of bias of each eligible study based on the Newcastle-Ottawa Scale [17]. Two authors (SP and KEF) assessed each study independently and discussed disagreements with the other two authors. The scale entails three domains (selection, comparability, and exposure) with several sub-questions, focusing on representativeness of the dataset, measurement of exposure/outcome, and control variables included. Since the original scale is only available for cohort and case-control studies, we based our quality analysis on a modified version of the scale $[9,10]$. Cross-sectional studies could be awarded a maximum of 6 points, while longitudinal studies had a maximum of 8 (see Additional file 2 for further details).

Due to the high heterogeneity of outcomes, we limited our analysis to a comparison of results based on their direction and level of significance. Furthermore, we focused our qualitative synthesis on methodological differences and how they influenced results in the studies. Finally, as a robustness check we focused our qualitative synthesis on studies which were awarded more than half of the maximum quality score indicating a low risk of bias.

\section{Results}

\section{Description of included studies}

Our search yielded 5674 records, resulting in 3570 papers after elimination of duplicates (Fig. 1). Through reference screening we identified 4 other articles. After the three-step screening process, thirty studies were considered eligible for the qualitative synthesis (Fig. 1).

As reported in Table 1 and detailed in Table 2, nineteen out of these thirty studies had a cross-sectional design
[18-36], ten had a longitudinal design [37-46] and one study used both kinds of designs [47]. Most studies were based on data from North America (15 studies), Europe (7 studies) or Australia (6 studies), while low and middle-income countries (LMICs) from Asia [24, 39] or Central America [31] were object of three studies only.

Most data were collected through large populationbased surveys, while only four of these studies linked those data to morbidity or administrative registries [28, $37,38,40]$. Almost half of the studies evaluated recent data collected from the year 2000 onwards. The other half analysed data collected in the last century, dating back until 1979.

Only a minority of studies focused on specific groups of employees [37, 38] or women [25, 42, 44], whereas the majority considered (population-based) samples from the general population.

While half of the studies focused on the elderly, the other half included samples from the whole working age population (aged 18-64). However, they generally carried out a stratified analysis for different age groups, so that the results are generally comparable among all studies on this regard.

Table 2 and Additional file 2 show that no study reached the maximum quality score. Three cross-sectional and three longitudinal studies gained half of the available points. This indicates a high risk of bias. The majority of studies were assigned a low score because, among other reasons, they used self-reported diabetes status as the exposure variable. Only a few studies based their analysis on more objective information from morbidity registries or formal blood tests [21, 26, 28, 37, 41]. Furthermore, the studies which adopted an "objective" definition of diabetes did not clearly indicate which pieces of information were used to carry out such definition, i.e. whether the status was defined on the basis of blood parameters (glycosylated haemoglobin, fasting or plasma glucose) or on the basis of a previous medical diagnosis reported by the participants. Additionally, in most cases the labour market outcomes were defined through structured interviews or questionnaires, resulting in a low scoring for several studies (Additional file 2).

In Table 2, we clustered the available studies according to the outcome(s) of interest. Despite the sorting into similar outcomes groups, the definitions of outcomes and control groups still varied considerably within each cluster, limiting the comparability of the studies included. For these reasons, any generalized comment or comparison of effect magnitude among the studies in this framework is not feasible, unfortunately.

\section{Effects on employment}

In general, as can be inferred from Table 2, the studies show a negative and statistically significant association between the presence of diabetes and the outcome 


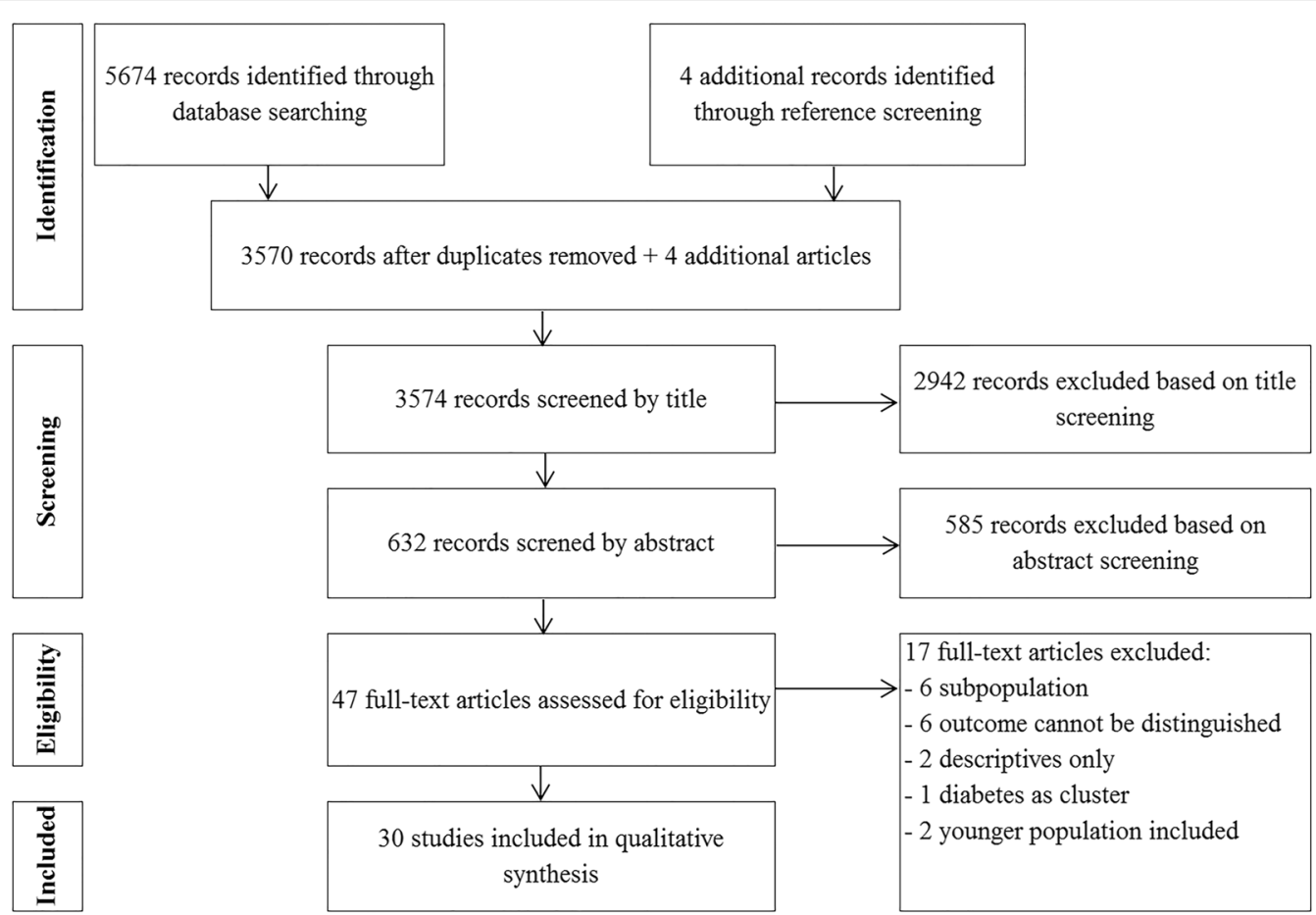

Fig. 1 PRISMA flowchart

"employment". However, the magnitude of the effect varies greatly between the studies considered. This might be due to differences in the mean sample ages, modelling techniques or outcome definitions. This negative effect does not change when we focus only on studies with a low risk of bias. Furthermore, considering the overall evidence, statistically significant coefficients for both genders are reported. However, within studies, estimated coefficients are generally higher in men than in women, indicating a stronger effect of diabetes on employment in males (see Table 2).

When focusing on studies from LMICs [24, 31, 39], diabetes does not show any effect on the employment chances of women, while the effect for men remains negative. This finding is in line with the overall results, but shows a much lower, if non-existent, effect in women compared to the other studies from HIC (high income countries). Furthermore, a few studies differentiated the analysis between type 1 and type 2 diabetes (T1DM and T2DM) $[25-28,43]$. They show that the negative effect of diabetes is actually driven by T2DM, since the coefficients on type 1 are generally insignificant or in some cases positive and statistically significant.

By applying different statistical methods, seven out of thirteen cross-sectional studies considering employment as the outcome variable tested for endogeneity of diabetes. In order to take this factor into account, authors employed either recursive multivariate probit models, jointly estimating the probability of diabetes, other comorbidities/complications (cardiovascular disease, depression, etc.) and employment, or used an instrumental variable (IV) approach, when genetic information (diabetes status of parents or siblings) was available. Not all studies detected the presence of endogeneity. Furthermore, if endogeneity was found to be present, modelling approaches aiming to account for endogeneity revealed either an under- or an overestimation of the coefficients compared to models without endogeneity. Hence, the overall picture is rather inconsistent.

To model the presence of comorbidities or complications, some studies included relevant variables as confounders in the analysis, without discussing the implications of their modelling choices [21, 22, 36, 44]. In contrast, other authors used these factors as additional controls in more complex model specifications, discussing their role with regard to the magnitude and the significance of the coefficients compared with simpler model specifications $[43,46]$. As a result, some coefficients on the diabetes variable lost their significance (see Table 2) or decreased (c.f. Table 2). In contrast, $\mathrm{Ng}$ et al. (2001) [27] carried out an additional analysis focusing only on the diabetes group and tested the impact of comorbidities. Their analysis shows that people suffering from diabetes and other comorbidities have a $12 \%$ lower probability of being in the labour force than people suffering from diabetes but without any complication. 
Table 1 Descriptive table of included studies

\begin{tabular}{|c|c|c|}
\hline Category & Characteristics & $\begin{array}{l}\text { Number } \\
\text { of studies }\end{array}$ \\
\hline \multirow[t]{2}{*}{ Design $^{a}$} & Cross sectional & 20 \\
\hline & Longitudinal & 11 \\
\hline \multicolumn{3}{|l|}{ Context } \\
\hline \multirow[t]{5}{*}{ Area $^{a}$} & North America & 15 \\
\hline & Europe & 7 \\
\hline & Australia & 6 \\
\hline & Asia & 2 \\
\hline & Central America & 1 \\
\hline \multirow[t]{2}{*}{ Period of data collection } & Before 2000 & 14 \\
\hline & After 2000 & 16 \\
\hline \multirow[t]{2}{*}{ Dataset } & Survey only & 26 \\
\hline & Survey + Register & 4 \\
\hline \multicolumn{3}{|l|}{ Participants } \\
\hline \multirow[t]{4}{*}{ Number of participants } & $<10,000$ & 11 \\
\hline & $\geq 10,000$ to $<50,000$ & 13 \\
\hline & $\geq 50,000$ to $<100,000$ & 5 \\
\hline & $>100,000$ & 1 \\
\hline \multirow[t]{3}{*}{ Population } & General population & 28 \\
\hline & Employees in the energy sector & 1 \\
\hline & Employees in the public sector & 1 \\
\hline \multirow[t]{3}{*}{ Sex } & Both & 27 \\
\hline & Only Women & 3 \\
\hline & Only Men & 0 \\
\hline \multirow[t]{3}{*}{$\mathrm{Age}^{\mathrm{b}}$} & 18 or older & 16 \\
\hline & 45 or older & 7 \\
\hline & 50 or older & 7 \\
\hline \multicolumn{3}{|l|}{ Definitions } \\
\hline \multirow[t]{3}{*}{ Diabetes definition } & self-report & 25 \\
\hline & register data & 3 \\
\hline & laboratory analysis & 2 \\
\hline \multirow[t]{5}{*}{ Diabetes type ${ }^{a}$} & T1DM only ${ }^{c}$ & 1 \\
\hline & T2DM onlyc & 1 \\
\hline & Both distinguished & 4 \\
\hline & Both undistinguished & 24 \\
\hline & Haemoglobin A1c > 6.5\% & 1 \\
\hline \multirow[t]{4}{*}{ Outcome } & Employment & 16 \\
\hline & Unemployment & 8 \\
\hline & Early retirement & 8 \\
\hline & Disability pension & 5 \\
\hline
\end{tabular}

${ }^{\mathrm{a}}$ These studies do not sum up to 30 . Some studies included more than one of the characteristics indicated

${ }^{\mathrm{b}}$ The indicated age refers to the youngest participant. Generally, the studies included only people maximum 64 or 65 years old. For details see Table 2 'T1DM: type 1 diabetes mellitus; T2DM: type 2 diabetes mellitus

\section{Effects on unemployment}

For the second outcome considered, i.e. "unemployment", heterogeneity in the outcome definition is particularly apparent. Groups of employed individuals are compared with very different samples of persons without occupation. From pooling corresponding evidence, it emerges that the presence of diabetes has no impact on the probability of having no occupation but still being economically active $[18,33,40,41]$. However, it is associated with a complete exit from the labour market [30, 32, 34, 41]. Furthermore, by differentiating the exposure variable in diabetes with/without complications, Kraut et al. (2001) [41] revealed that people suffering from diabetes with complications are more likely to exit the labour force compared to individuals not suffering from diabetes, whereas this observation does not hold for people with diabetes without complications.

\section{Effects on early retirement and permanent disability pension}

In general, studies focusing on early retirement revealed a positive association between the presence of diabetes and the probability of retiring early. In contrast, two studies stratified their analyses with respect to gender and revealed only weak evidence for either women or men [29, 39]. However, one of these studies shows a high risk of bias [29], while the other one entails a low number of observations, probably leading to a lack of significance in the final result [39].

Studies evaluating the fourth outcome, viz. "permanent disability pensions", revealed a positive association with the presence of diabetes. In the paper by Ervasti et al. (2016) [37] several models with different comorbidities and complications are reported. After introducing corresponding confounders, coefficients on diabetes remained positive and statistically significant, but their magnitude diminished (see Table 2).

\section{Robustness checks}

Generally, leaving out studies at high risk of bias does not change the pattern of synthesised results remarkably for different outcomes. No study focusing on unemployment, early retirement or disability pension distinguished between T1DM and T2DM or considered endogeneity of diabetes. Furthermore, only two studies stratified the analysis for gender, and several studies included comorbidities or complications as confounders, potentially adding other sources of bias to the analysis.

\section{Discussion}

Summary of evidence and interpretation

We identified 30 studies, which evaluated the impact of diabetes on labour market outcomes, which imply a complete absence of any occupation. The available 


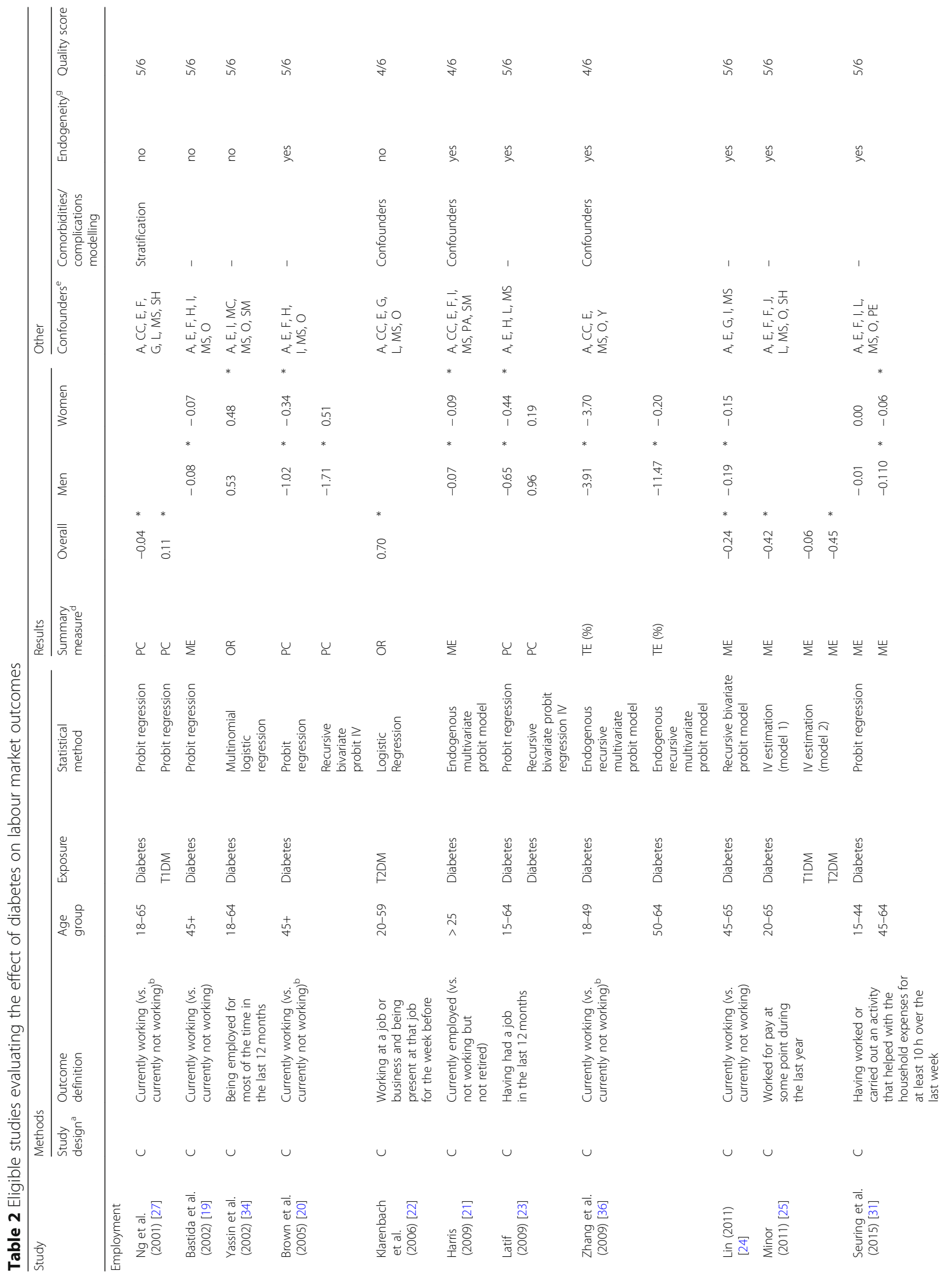




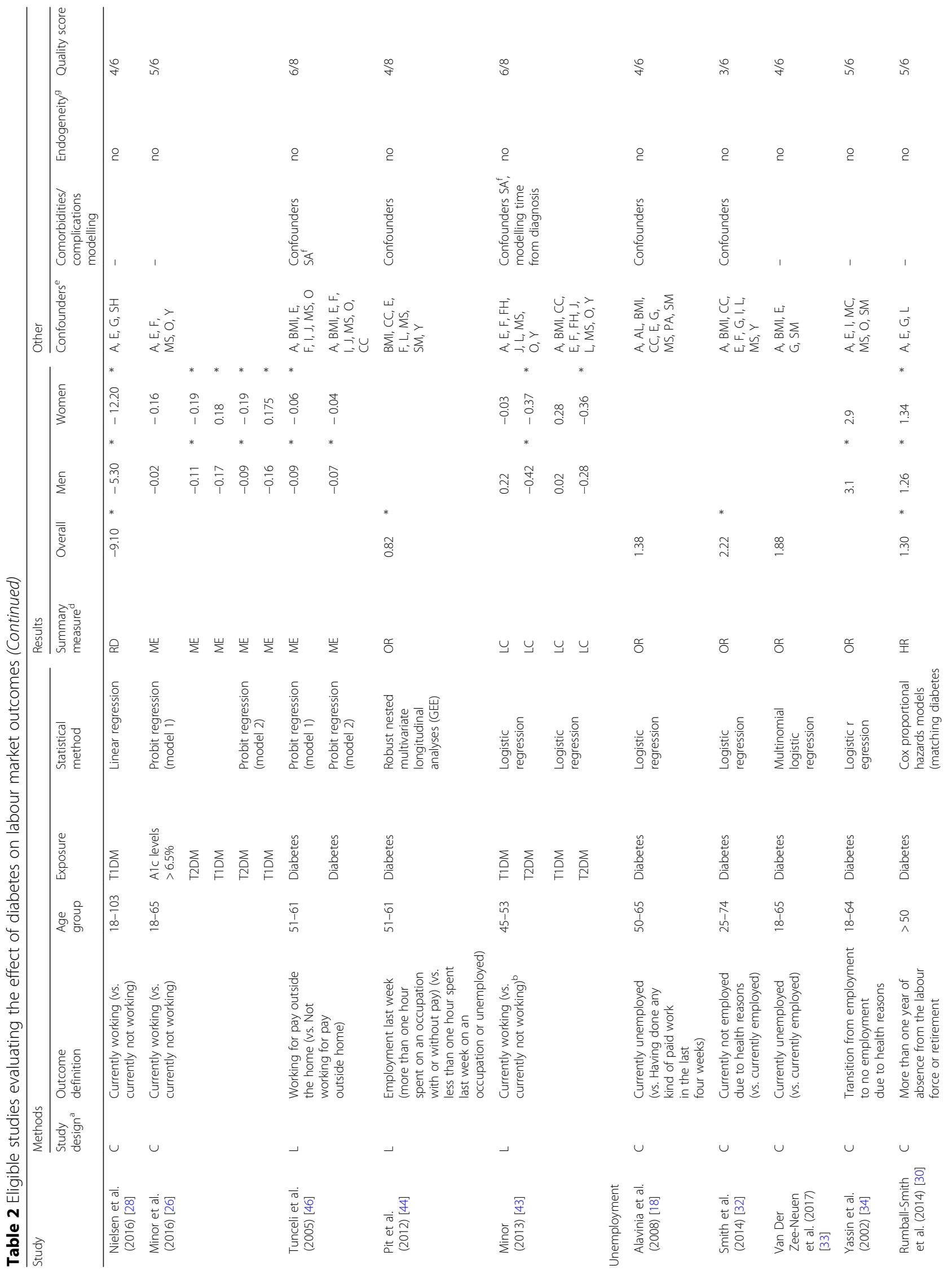




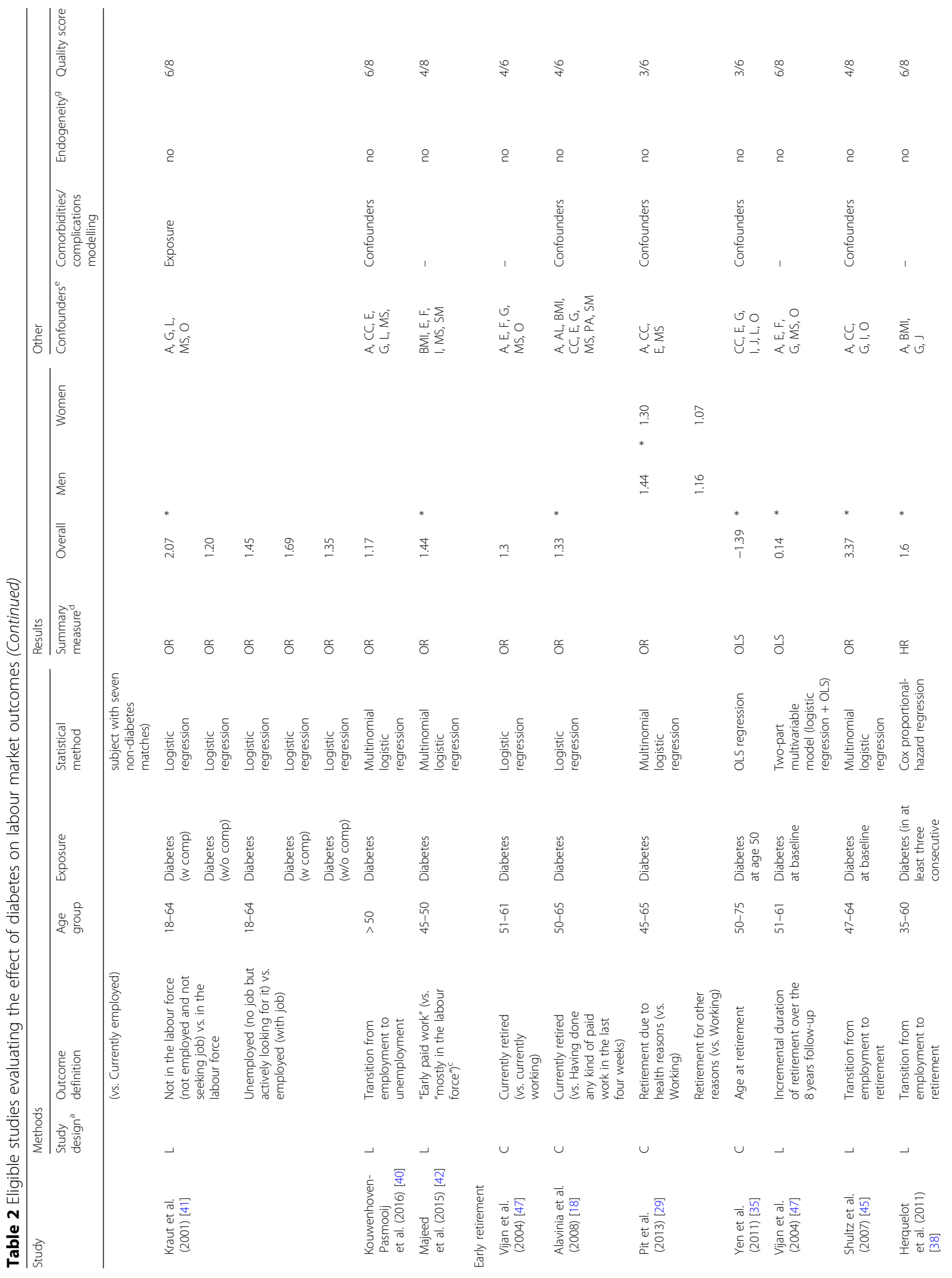




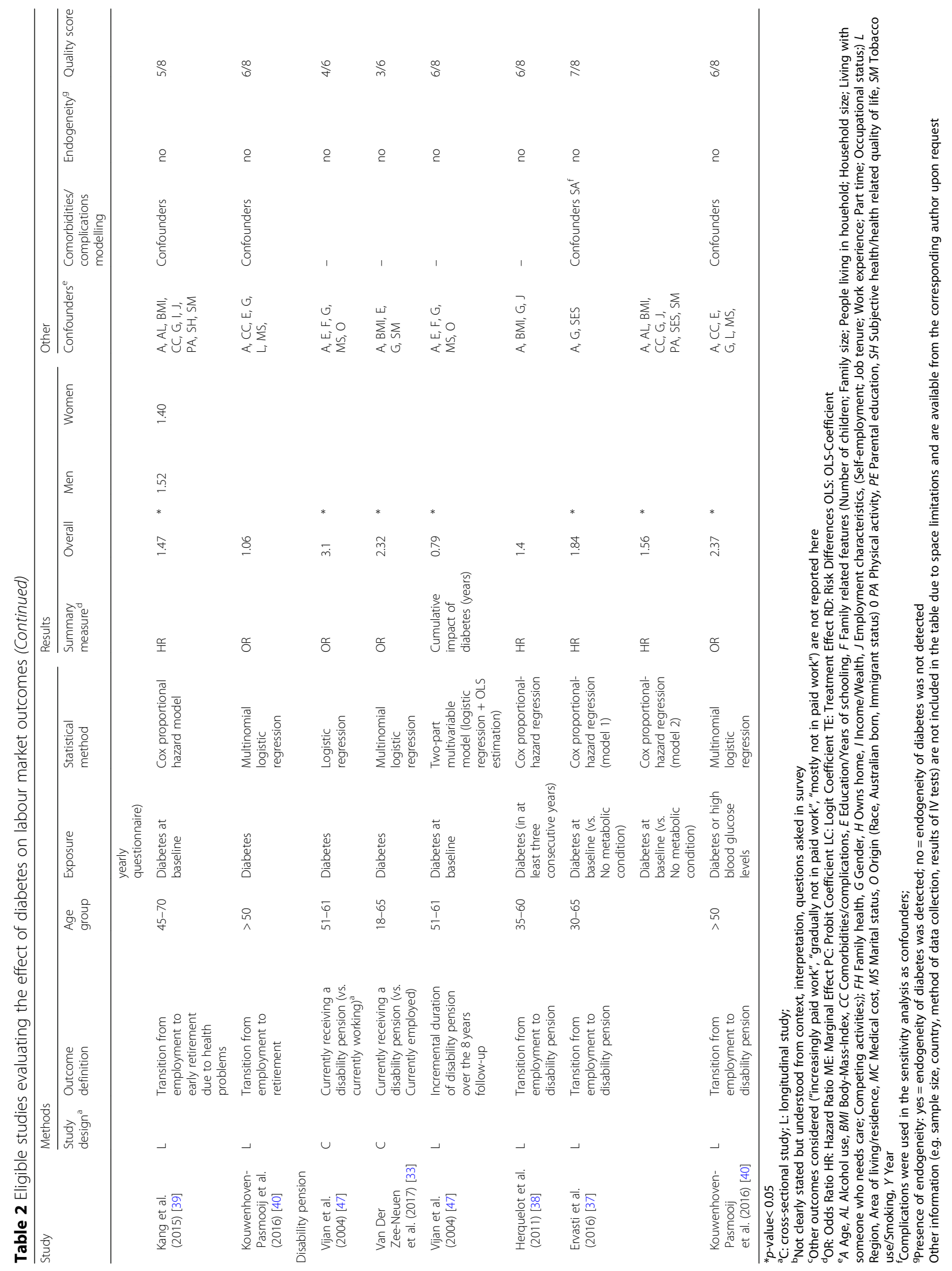


studies were quite heterogeneous in terms of definition of outcomes, age of the population considered and statistical method used even within the four outcome clusters we identified. Generally, the studies included provide consistent evidence that diabetes is negatively associated with employment and that diabetes patients are more likely to retire early, be fully out of the labour force and to receive a full and permanent disability pension, although effects may vary across subgroups.

The studies included also show considerable differences in the methods used, which could significantly impact the results. Furthermore, evaluations are often based on an extremely simplified modelling of diabetes, its dynamics and its progression, resulting in potential sources of bias. In this context, the majority of data is based on self-reported diabetes status and often no heterogeneity factors or endogeneity of the labour market outcomes are considered, resulting in lower quality scores for several studies included.

Specifically, a stratified analysis using potential sources of heterogeneous effects, such as gender, age, age at retirement or diabetes type, was inconsistently carried out throughout the studies, limiting the comparison of results regarding different groups within the scope of this review. In fact, a consistent stratified analysis between genders is available only for the outcome "employment". For the other outcomes, only isolated evidence with a high risk of bias could be found [29, 30, 34, 39]. As shown in many of the studies included $[16,19,25,27$, $30,32,35,39,42]$ and in a previous review [7], both men and women suffering from diabetes have higher chances of adverse labour market outcomes, but within the same studies, the effect is generally higher for men than for women. However, no study furnished an evidence-based explanation of this result. The main interpretation is that, since the employment chances of elder females are already low due to several other factors (e.g. providing informal care, traditional household regimes), diabetes influences the employment chances of women in a less disruptive way than those of men. In this context, also the differences between studies from LMICs and other countries should be emphasized: the effect of diabetes for the employment and early retirement chances of women in LMICs is never significant, while the effect for men is in line with those observed in HIC [24, 31, 39]. The non-significant effect for women should be put in the right context and should be interpreted in the light of labour market differences, regarding most notably the social security systems and the role of women in society, which still characterize the divide between HIC and LMICs and which could significantly affect the employment chances of women in the first place. However, in line with previous studies [11], this review highlights also the paucity of evidence regarding the differences between HIC and LMICs, since only three of the included studies focused on the latter [24, $31,39]$, and thus highlights the need for more research on these differences.

Most studies were based on large survey data, where diabetes status was self-reported (see Table 1). Although previous studies showed that there is a high correspondence between self-report and objective diagnosis [48, 49], this implies that most of the available evidence regarding the effect of diabetes on labour market outcomes bases its analysis and conclusions on a subjective measure of diabetes and is thus potentially open to bias. This bias is expected to be upwards, since the undiagnosed cases are probably those who also do not show any symptom or impairment from the disease, and as such are much less likely to leave the labour force due to diabetes. This potential pitfall is reflected in the lower quality score assigned to those studies based on self-report of diabetes and should be considered as an important limitation of the available evidence in this field.

Furthermore, in the same studies, no other information about age at onset, diabetes type, severity or medications was available, according to the publications identified. One important distinction in this context is that between T1DM and T2DM. Although the prevalence of T1DM is usually low [1], not controlling for this difference could cause a downward bias and, thus, an underestimation of the effect of T2DM on employment. In fact, the few studies that distinguish between the two diabetes types show that the negative effect of diabetes on employment is actually driven by T2DM, since the coefficients on T1DM are either insignificant or even significantly positive. Furthermore, T1DM and T2DM are two distinct conditions, with two different aetiologies and ways of coping with the illness. Therefore, this difference should be taken into account when modelling diabetes. For example, in absence of more detailed information, the age at onset could offer a good approximation, as already done in some of the studies included $[25,26]$.

Most studies also adopted a very simplified modelling of comorbidities and complications. These factors can play a crucial role in the ability to work of diabetes patients over the life course and, thus, should be considered when modelling diabetes and labour market outcomes. There is no consensus on how to take them into account. In most of the studies considered, they are either not taken into account or are modelled as confounders. However, as highlighted by some authors [25], simply adding them as confounders could be problematic, since they might be highly correlated with diabetes or a result of common unobserved factors. Therefore, including them as covariates into the model could result in biased estimates for the diabetes variable. In isolated cases comorbidities and complications are included [1] as confounders in different 
versions of the model as further specification [37, 43, 46], [2] as a way to differentiate the exposure variable (diabetes with/without complications) [41] or [3] as exposure in a further analysis focusing only on the diabetes group [27]. These three implementations show that adding such confounders leads to a change in the magnitude or in the significance of the coefficient on the diabetes variable [37, 43, 46]. In addition, Kraut et al. (2001) [41] showed that only diabetes with complications leads to a full labour market exit. Ng et al. (2001) [27] also revealed that people suffering from diabetes with complications have a higher chance of being out of the labour force than people suffering from diabetes without complications.

A further issue, only addressed in a few studies, is the problem of reverse causality or endogeneity of diabetes in labour market outcome models. Typical ways for taking this problem into account include recursive multivariate probit approaches $[20,21,23,24]$ or the use of genetic instrumental variables $[25,31]$. Results from studies taking endogeneity into account generally differed in two aspects: (i) the actual endogeneity of the diabetes variable and (ii) the direction of the bias in the regression coefficients with respect to the basic model without endogeneity. Overall, diabetes was not found to be consistently endogenous in each study considered and for every gender subgroup. Furthermore, while comparing the results from models with and without endogeneity within the same study, no clear direction of the bias of the coefficients could be highlighted (see Table 2). Therefore, since the pattern of presence and effect is not clear, endogeneity should always be tested for in this context and the limitations of results should be discussed carefully.

\section{Strengths and limitations}

This review specifically gathered evidence regarding the effect of diabetes on all labour market outcomes involving the complete absence of occupation. Hence, it complements related reviews, which focused on other productivity outcomes [9] or reviewed part of the included outcomes as a secondary aim [11]. Furthermore, in the present review, we paid specific attention to the methods used, providing ground for an evidence-based discussion on how to produce credible and robust findings both from an economic and a statistical point of view.

However, our study may suffer from some limitations. First, we have adopted rather restrictive inclusion criteria. We searched three databases and we included only articles already published in peer-reviewed journals, starting from the year 2000. Therefore, the review might suffer from publication bias. However, the large number of studies initially retrieved after an independent screening by two researchers and a comprehensive reference check allowed us to apply such restrictive criteria in order to report the most robust evidence available.
Second, we based our quality and risk of bias assessment on the Newcastle-Ottawa Scale [17], as already done in similar reviews $[9,10]$. Besides the transparent procedure of evaluation, the scale had to be modified for our specific case, which prevents comparability to a certain extent (for detailed explanation see Additional file 2). Furthermore, the scale is actually suitable for evaluating epidemiological studies involving clinical outcomes but could still be adapted to our specific question and context. Although the scale represents the best instrument available to our knowledge, this problem should be taken into account in further studies, aiming at improving also quality and risk of bias assessment.

\section{Implications for practice, policy, and research}

The aggregated evidence available reveals that generally, individuals suffering from type 2 diabetes mellitus are more likely to fully exit the labour market early, retire early and receive a permanent disability pension. Both men and women are affected, but the probability of employment of men is affected stronger than that of women. Diabetes can be endogenous in the labour market outcomes, but it is not clear why and in which cases it is present and how coefficients are influenced.

Maintaining and possibly also extending the ability to work of older workers is one of the primary goals of current pension reforms. This study shows, however, that chronically ill individuals suffering from T2DM, might not be able to maintain their employment status and will therefore exit the labour market earlier. Since T2DM prevalence is rising, not only in high- but also in low- and middle-income countries [1], a considerable effort should be undertaken to improve and prolong the ability to work of diabetes individuals. Specific attention should be paid to developing and increasing the efficacy of evidence-based prevention and management programs.

Finally, the existing evidence should be improved, specifically investigating the underlying dynamics and establishing and strengthening the link to practice. First, future cost studies investigating the indirect costs of diabetes should take the complete absence of an occupation due to diabetes or its complications into account. Failing to consider this aspect could lead to a severe underestimation of the burden this condition is imposing. Second, future studies will need to differentiate between gender and/or diabetes type, while also checking specifically for the endogeneity of diabetes. These methods should be applied for every outcome, not only for the presence versus absence of employment. Third, the issue of diabetes endogeneity should be discussed for each study, since no pattern of presence and effect could be found. Understanding how the underlying processes and effects work, being it through reverse causality or through unobserved factors, could also prove helpful in understanding how a 
chronic life-style illness impacts the outcomes considered. Lastly, the available studies adopt an extremely simplified definition and modelling of diabetes, its progression, its severity and its complications and comorbidities. Further research should rely on more objective ways to determine diabetes. Also, it should improve the understanding of which factors and dynamics actually lead to adverse labour market outcomes and should include different modelling strategies on how comorbidities and complications actually work. Furthermore, additional aspects of the illness, such as efficiency of management, health literacy, and medication adherence $[50,51]$, should be included in the analysis, to gather further understanding on underlying factors and allow for the individualisation of concrete starting points for practical intervention.

\section{Conclusions}

This systematic literature review indicates that type 2 diabetes mellitus, but not type 1 , is associated with lower productivity. We further found that the effect of diabetes is generally stronger in men than in women. In addition, the present study reveals that one of the largest potential sources of bias is the use of self-reported measures of diabetes, not confirmed by physicians or formal blood tests. Finally, the studies showed no consensus regarding the correct modelling strategy of diabetes and labour market outcomes. Only some of them considered possible endogeneity, or only partly discussed their modelling choices regarding the role of complications and comorbidities. Thus, the review highlights the need for improving the current practice of modelling diabetes and for understanding how the illness is connected with the outcomes. This is not only important for the accurate determination of indirect costs, but could also prove useful in the establishment of evidence-based prevention and disease management programs.

\section{Additional files}

Additional file 1: Search strategy. This file contains a detailed account of the databases and terms/keywords and restrictions used in our search strategy for one database (PubMed). (PDF $156 \mathrm{~kb}$ )

Additional file 2: Newcastle-Ottawa Scale and quality scores. This file contains a detailed overview and explanation of the Newcastle-Ottawa Scale used to assess quality of the retrieved studies. The file entails also a detailed overview of the scores for each study in each dimension. (PDF $271 \mathrm{~kb}$ )

\section{Abbreviations}

T1DM: Type 1 Diabetes Mellitus; T2DM: Type 2 Diabetes Mellitus; Haemoglobin A1c: glycosylated haemoglobin; LMIC: Low and middle income countries; HIC: High income countries
Funding

None.

Availability of data and materials

All data generated or analysed during this study are included in this published article and its supplementary information files.

\section{Authors' contributions}

All authors conceptualized the review and formulated the research question. SP and KEF developed and carried out the research strategy, independently screened the manuscripts, retrieved the information and evaluated the results. Disagreements were discussed with $M L$ and $L S$, who provided guidance during the process. SP drafted the manuscript. KEF, ML and LS critically revised and contributed to the manuscript. All authors read and approved the final manuscript.

Ethics approval and consent to participate

Not applicable.

Consent for publication

Not applicable.

\section{Competing interests}

The authors declare that they have no competing interests.

\section{Publisher's Note}

Springer Nature remains neutral with regard to jurisdictional claims in published maps and institutional affiliations.

Received: 13 January 2018 Accepted: 14 December 2018

Published online: 07 January 2019

\section{References}

1. International Diabetes Federation. IDF Diabetes Atlas. In: Brussels; 2017.

2. Boyle JP, Engelgau MM, Thompson TJ, Goldschmid MG, Beckles GL, Timberlake DS, et al. Estimating prevalence of type 1 and type 2 diabetes in a population of African Americans with diabetes mellitus. Am J Epidemiol. 1999;149(1):55-63.

3. Bruno G, Runzo C, Cavallo-Perin P, Merletti F, Rivetti M, Pinach S, et al. Incidence of type 1 and type 2 diabetes in adults aged 30-49 years. Diabetes Care. 2005:28(11):2613-9.

4. Evans J, Newton RW, Ruta DA, MacDonald TM, Morris AD. Socio-economic status, obesity and prevalence of type 1 and type 2 diabetes mellitus. Diabetic Med. 2000;17(6):478-80.

5. Yach D, Stuckler D, Brownell KD. Epidemiologic and economic consequences of the global epidemics of obesity and diabetes. Nat Med. 2006:12(1):62-6.

6. Albright A. The National Diabetes Prevention Program: from research to reality. Diabetes Care Educ Newsl. 2012;33(4):4

7. Fuchs $\mathrm{S}$, Henschke $\mathrm{C}$, Blümel M, Busse R. Disease management programs for type 2 diabetes in Germany: a systematic literature review evaluating effectiveness. Dtsch Arztebl Int. 2014;111(26):453.

8. Lynne D. Diabetes disease management in managed care organizations. Dis Manag. 2004:7(1):47-60.

9. Breton M-C, Guénette L, Amiche MA, Kayibanda J-F, Grégoire J-P, Moisan J. Burden of diabetes on the ability to work. Diabetes Care. 2013;36(3):740-9.

10. Chaker L, Falla A, Lee SJ, Muka T, Imo D, Jaspers L, et al. The global impact of non-communicable diseases on macro-economic productivity: a systematic review. Eur J Epidemiol. 2015;30(5):357-95.

11. Seuring T, Archangelidi $O$, Suhrcke M. The economic costs of type 2 diabetes: a global systematic review. PharmacoEconomics. 2015;33(8):811-31.

12. Ettaro L, Songer TJ, Zhang P, Engelgau MM. Cost-of-illness studies in diabetes mellitus. PharmacoEconomics. 2004:22(3):149-64.

13. American Diabetes Association. Economic costs of diabetes in the U.S. in 2017. Diabetes Care. 2018:41(5):917-28.

14. Moher D, Liberati A, Tetzlaff J, Altman DG. Preferred reporting items for systematic reviews and meta-analyses: the PRISMA statement. PLoS Med. 2009;6(7):e1000097.

15. American Diabetes Association. Diagnosis and classification of diabetes mellitus. Diabetes Care. 2014;37(Supplement 1):S81-90. 
16. Cochrane Consumers Communication Review Group. Data extraction template. http://cccrg.cochrane.org/ Aa, editor 2011.

17. Wells G, Shea B, O'Connell D, Peterson J, Welch V, Losos M, et al. NewcastleOttawa Scale. Hospital Research Institute Ottawa. http://www.ohri.ca/ programs/clinical_epidemiology/oxford.asp. 2006; Access date 20 Dec 2018.

18. Alavinia SM, Burdorf A. Unemployment and retirement and ill-health: a cross-sectional analysis across European countries. Int Arch Occup Environ Health. 2008;82(1):39-45.

19. Bastida E, Pagan JA. The impact of diabetes on adult employment and earnings of Mexican Americans: findings from a community based study. Health Econ. 2002;11(5):403-13.

20. Brown HS 3rd, Pagan JA, Bastida E. The impact of diabetes on employment: genetic IVs in a bivariate probit. Health Econ. 2005;14(5):537-44

21. Harris A. Diabetes, cardiovascular disease and labour force participation in Australia: an endogenous multivariate probit analysis of clinical prevalence data. Econ Rec. 2009;85(271):472-84.

22. Klarenbach S, Padwal R, Chuck A, Jacobs P. Population-based analysis of obesity and workforce participation. Obesity (Silver Spring, Md). 2006;14(5):920-7.

23. Latif E. The impact of diabetes on employment in Canada. Health Econ. 2009;18(5):577-89.

24. Lin S-J. Estimating the impact of diabetes on employment in Taiwan. Econ Bull. 2011;31(4):3089-102.

25. Minor $T$. The effect of diabetes on female labor force decisions: new evidence from the National Health Interview Survey. Health Econ. 2011;20(12):1468-86.

26. Minor T. Macewan JP. A comparison of diagnosed and undiagnosed diabetes patients and labor supply. Econ Hum Biol. 2016;20:14-25.

27. $\mathrm{Ng} \mathrm{YC,} \mathrm{Jacobs} \mathrm{P,} \mathrm{Johnson} \mathrm{JA.} \mathrm{Productivity} \mathrm{losses} \mathrm{associated} \mathrm{with} \mathrm{diabetes} \mathrm{in}$ the U. S Diabetes Care. 2001;24(2):257-61.

28. Nielsen HB, Ovesen LL, Mortensen LH, Lau CJ, Joensen LE. Type 1 diabetes, quality of life, occupational status and education level - a comparative population-based study. Diabetes Res Clin Pract. 2016;121:62-8.

29. Pit SW, Shrestha R, Schofield D, Passey M. Partial and complete retirement due to ill-health among mature age Australians. Public Health. 2013;127(6):561-71.

30. Rumball-Smith J, Barthold D, Nandi A, Heymann J. Diabetes associated with early labor-force exit: a comparison of sixteen high-income countries. Health Aff. 2014;33(1):110-5.

31. Seuring T, Goryakin $Y$, Suhrcke $M$. The impact of diabetes on employment in Mexico. Econ Hum Biol. 2015;18:85-100.

32. Smith P, Chen C, Mustard C, Bielecky A, Beaton D, Ibrahim S. Examining the relationship between chronic conditions, multi-morbidity and labour market participation in Canada: 2000-2005. Ageing Soc. 2014;34(10):1730-48.

33. Van der Zee-Neuen A, Putrik P, Ramiro S, Keszei A, De Bie R, Chorus A, et al. Work outcome in persons with musculoskeletal diseases: Comparison with other chronic diseases \& the role of musculoskeletal diseases in multimorbidity. BMC Musculoskelet Disord. 2017;18(1): https://doi.org/10. 1186/s12891-016-1365-4.

34. Yassin AS, Beckles GL, Messonnier ML. Disability and its economic impact among adults with diabetes. J Occup Environ Med. 2002;44(2):136-42.

35. Yen L, McRae I, Jeon YH, Essue B, Herath P. The impact of chronic illness on workforce participation and the need for assistance with household tasks and personal care by older Australians. Health Soc Care Community. 2011;19(5):485-94.

36. Zhang $X$, Zhao X, Harris A. Chronic diseases and labour force participation in Australia. J Health Econ. 2009;28(1):91-108.

37. Ervasti J, Kivimäki M, Pentti J, Salo P, Oksanen T, Vahtera J, et al. Health-and work-related predictors of work disability among employees with a cardiometabolic disease-a cohort study. J Psychosom Res. 2016;82:41-7.

38. Herquelot $\mathrm{E}$, Gueguen A, Bonenfant S, Dray-Spira R. Impact of diabetes on work cessation: data from the GAZEL cohort study. Diabetes Care. 2011;34(6):1344-9.

39. Kang MY, Yoon C, Yoon JH. Influence of illness and unhealthy behavior on health-related early retirement in Korea: results from a longitudinal study in Korea. J Occup Health. 2015;57(1):28-38

40. Kouwenhoven-Pasmooij TA, Burdorf A, Roos-Hesselink JW, Hunink MGM, Robroek SJW. Cardiovascular disease, diabetes and early exit from paid employment in Europe; the impact of work-related factors. Int J Cardiol. 2016;215:332-7.

41. Kraut A, Walld R, Tate R, Mustard C. Impact of diabetes on employment and income in Manitoba. Canada Diabetes Care. 2001;24(1):64-8.

42. Majeed T, Forder P, Mishra G, Byles J. Women, work, and illness: a longitudinal analysis of workforce participation patterns for women beyond middle age. J Women's Health. 2015;24(6):455-65.

43. Minor T. An investigation into the effect of type i and type II diabetes duration on employment and wages. Econ Hum Biol. 2013;11(4):534-44.
44. Pit SW, Byles J. The association of health and employment in mature women: a longitudinal study. J Women's Health. 2012;21(3):273-80.

45. Shultz KS, Wang M. The influence of specific physical health conditions on retirement decisions. Int J Aging Human Dev. 2007;65(2):149-61.

46. Tunceli K, Bradley CJ, Nerenz D, Williams LK, Pladevall M, Lafata JE. The impact of diabetes on employment and work productivity. Diabetes Care. 2005;28(11):2662-7.

47. Vijan S, Hayward RA, Langa KM. The impact of diabetes on workforce participation: results from a national household sample. Health Serv Res. 2004;39(6 Pt 1):1653-69.

48. Goto A, Morita A, Goto M, Sasaki S, Miyachi M, Aiba N, et al. Validity of diabetes self-reports in the Saku diabetes study. J Epidemiol. 2013;23(4):295-300.

49. Jackson JM, DeFor TA, Crain AL, Kerby TJ, Strayer LS, Lewis CE, et al. Validity of diabetes self-reports in the Women's Health Initiative. Menopause-J N Am Menopause Soc. 2014:21(8):861-8.

50. Davis-Ajami ML, Nahata MC, Reardon G, Seiber EE, Balkrishnan R. Associations between joblessness and oral anti-diabetic medication adherence in US diabetic working-age adults. Health Outcomes Res Med. 2012;3(3):e139-e51.

51. Rak EC. Employment outcomes in persons with diabetes: the role of health literacy and diabetes management self-efficacy. Rehabil Couns Bull. 2014; 57(3):159-69.

Ready to submit your research? Choose BMC and benefit from:

- fast, convenient online submission

- thorough peer review by experienced researchers in your field

- rapid publication on acceptance

- support for research data, including large and complex data types

- gold Open Access which fosters wider collaboration and increased citations

- maximum visibility for your research: over $100 \mathrm{M}$ website views per year

At $\mathrm{BMC}$, research is always in progress.

Learn more biomedcentral.com/submissions 